\title{
From Waterfall to Agile software: Development models in the IT sector, 2006 to 2018. Impacts on company management
}

\author{
Alina Mihaela Dima \\ Faculty of Business Administration, \\ the Bucharest University of Economic Studies \\ Romania \\ alinamihaeladima@yahoo.com \\ Maria Alexandra Maassen \\ Faculty of Business Administration, \\ the Bucharest University of Economic Studies \\ Romania \\ maria_nichifor@hotmail.com
}

Abstract. The IT sector has been one of the most innovative fields, encountering tremendous development in the last three decades. As many other sectors of activity have been also digitalized, new software development models have been established due to changing customer needs, as well as due to the increased pressure of innovation necessity. This has influenced the traditional models of software development management in the direction of more complex organizations matrices and cooperation between several layers of management, employees and other departments. The objective of the present paper is to determine the main software development models used in the IT sector between 2006-2018, as well as their impact on companies' management. For this, Delphi method with interviews and questionnaires was applied. The results reveal the evident trend towards the Agile software development model, that implies rapid implementation of new software features in order to satisfy new market needs. The relevance of the present paper lies in the fact that as technology dynamics change, software development models evolve, this aspect being worthy of observation on the company level. Although such models have been widely described in scientific literature by now, few studies have provided insights on the company level regarding specific features and changes in software development models.

Keywords: Waterfall, Agile, software development.

JEL Classification: M11, M12, M15 


\section{INTRODUCTION}

The IT industry has become one of the leading industries worldwide, contributing with innovative devices and software programmes, that support all current fields of activity, such as medicine, business, education and social networking. The IT industry market exceeded 4,5 trillion $\$$ in 2017 , the United States being the largest technology market in the world with its 31\% share, or 1,5 trillion \$ in 2018 alone, respectively (Comptia, 2018). As technology is evolving, the need for newer innovations is also becoming more dynamic and customer preferences and needs change more rapidly than ever before. Thus, life cycles of IT products are getting shorter, new versions or new products being needed to satisfy newer customer needs. This aspect has led to the development of more software development models, the main ones being Waterfall and Agile, that propose management models of software development depending on the dynamics of the IT business environment, product features and organizational structure. While the Agile model is considered to bring in incremental changes, allowing a software development project to become more flexible in response to changing requirements, the Waterfall model is usually treated as a more conservative type of a model, in which requirements are established and transmitted from the beginning and only after product release the feedback is provided (Stober \& Hansmann, 2010). However, new versions of the Waterfall model already include the features of Agile management, and also many other changes in software development models are becoming visible as the competition in the field increases.

Scientific literature refers mostly theoretically to these models and emphasizes the need of the Agile management model features, such as incremental changes' implementation, frequent customer feedback and stronger cooperation between management and department levels in order to get more competitive products, as it is mentioned in (Puri, 2009; Canty, 2015; Cobb, 2015; Kihlström, 2016).

The objective of this paper is to inquire practically into the software development models used by IT companies between 2006-2018 and their impacts on the management of projects and teams. For the purposes of this research, a selection of experts from 19 main international IT companies have been interviewed through the Delphi method, bringing a valuable insight aboutthe software models used in their companies, special attention was paid to the use of the Agile model as compared to the Waterfall model. The relevance of this subject lies in the novelty of providing an overview of specific features and changes in software development models in the IT field, these being described in scientific literature mostly theoretically, but not specifically in the cases of certain organizations.

Two hypotheses have been formulated prior to the research in order to be tested through the practical inquiry:

H1. The main trend after 2013 in IT companies was the Agile model supporting continuous changes according to continuous customer feedback changing competition requirements.

H2. The future trend of software development models in the next five years will be the Agile model focused on dynamic management of teams and continuous communication with customers and stakeholders, as well as other new emerging models changes.

The paper is structured as follows: literature review, namely, information on the available scientific literature is presented along with the already obtained results on the subject, followed by methodology, respectively, the main methods used in the practical part of the study, finally, findings and results of the practical inquiry are laid out along with the conclusions.

\section{LITERATURE REVIEW}

As mentioned the main two models of software development in the IT sector are Waterfall and Agile, each of these providing different characteristics, advantages and disadvantages to both parties, company and customers, depending on the size of the project, product profile, competition field and other. The 
Waterfall model assumes a following of sequences in phases of the software development, starting with the instructions regarding the customer requirements and afterwards followed by their practical implementation with the product construction, as shown in Figure 1:

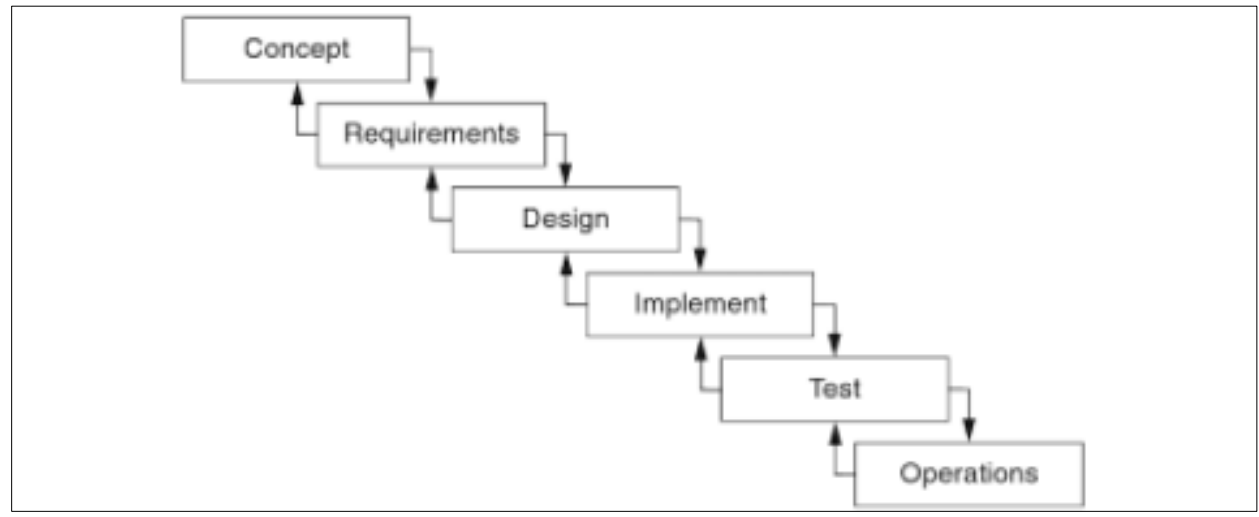

Figure 1. Waterfall phases

Source: Westfall, 2010

As one can observe in Figure 1 the classical approach of the Waterfall model starts with the concept inquiry, namely with analysis of requirements. The model is considered to offer a well-defined set of criteria and requirement indications before actually starting the design phase and implementation of the project, thus, offering a basis plan of the project before starting and continuing in an orderly sequence of phases. The main issue with the Waterfall model is that it cannot ensure quickly changes of stakeholders requirements until the project is finished or nearly finished, thus, being more appropriate for projects that are considered to have more stable or unchanged requirements at least for a longer period of time (Vallabhaneni, 2018). According to Othman et al. (2017) the waterfall model implies one phase has to be finished before the other one starts, the risk being high that errors from the previous phase can be transmitted to the next phase, as verification occurs at the end of the software development or close to the end phase. This type of model sustains a more traditional type of management organization, where requirements circulate from top management to basis management and further on to employees and minimal or no contact with customers or other stakeholders occurs with developers teams. Requirements are usually transmitted indirectly through organization members.

In the case of projects where requirements change rapidly or where competition in the product field is increased and new features have to be implemented quickly, the Agile model is considered more appropriate due to its increased flexibility to customer requirements implementation and frequent product releases. The Agile model has itself two main versions of software development management, namely the Scrum method and the Test driven development.

The Scrum method is a version of the Agile model, that supports also a quick implementation of new customer requirements. First a product backlog is created, namely, a list, where the customer requirements priorities are selected, while afterwards requirements are split into short term objectives, named Sprints (maximum three to four weeks), that are established by the project manager or scrum master, as they can be named (Linz, 2014). An essential part of a successful implementation of the Scrum method is the involvement of the development teams, that have to meet daily to discuss software development progress and obstacles in order to quickly implement the requirements. Cooperation with other teams from the company can be necessary as well. As each sprint is finished a new release of the software should occur (Chandrasekara, 2017). 


\section{The basic principles of the Scrum process}

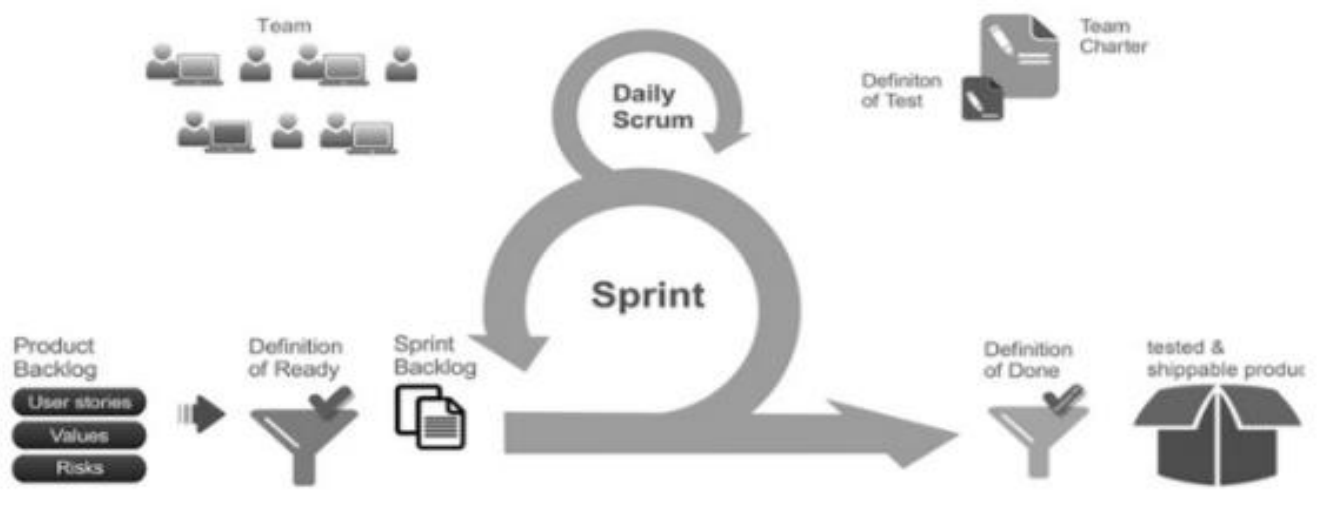

Figure 2. The Scrum method

Source: Linz, 2014

The Test Driven Development is another version of managing software development within the Agile method. This method offers a new approach as test is written before the actual start of software development through coding, thus, it starts with establishing the requirements for the new product feature and with the testing of a first version of the product, being followed by the feature implementation through coding and testing (Paranj, 2017). If after coding the test is not successfully passed it implies the feature was not implemented, whereas when all tests are passed it means it was successfully implemented. This method is considered to reduce the amount of errors through the frequent testing.

These software development methods, as mentioned, offer possibilities of organizing the management and team involvement of companies, as well as the product creation and improvement itself being essential to adaptation to environment characteristics, increased competition from other IT companies and thus, increased customer requirements and preferences for continuous innovations in the field.

Most of the scientific literature currently presents descriptions of the software development models in the IT field, but it does not present significant results from companies. Most publications found are description of the models, but do not offer an overview of the situation in IT companies, that apply the models.

For example, a study regarding the characteristics and effects of software development models including Waterfall and Agile in the IT field was done by Kaur and Sengupta (2011), however this study focused on describing the models and the failure rates and motives of their application, mainly due to factors, such as: miscommunication between IT and business, re-work time consumption, poor requirements gatherings, analysis and management. Pycek (2009) also describes characteristics and advantages of the models, such as for Agile the early detection of errors, enhancing team and stakeholder communication, reducing risk of the project and other. This perspective is also more theoretical. Other authors also present theoretical aspects of implementing software development models, such as the different types of Agile model versions and Waterfall but also mainly from a theoretical perspective (Ashisdeep et al., 2016; Chandra, 2015; Krishna et al., 2012; McHugh et al., 2013).

Therefore, the present paper brings an overview of the situation of two of the main software development models in the IT field, respectively Waterfall and Agile, within some of the main IT players on the global market. The models are not only presented theoretically, but specific characteristics, effects 
on company culture, perceptions from employees and other aspects from within these companies are also emphasized.

\section{METHODOLOGY}

In order to ensure a practical approach the Delphi method based on interviews and questionnaires was used to interview experts from 19 international IT companies, among which some of the most important IT market players globally. The Delphi method (Richardson, Abrahamsson, 2005) followed the theoretical phases of: consulting literature review on the matter inquired, defining the objective of the research, preparing questionnaires and interviews, discussions with the participants, analysis of the results, informing the participants on the results, second part of discussions with participants, analysis of results and final report and informing participants on final reports.

Most experts, that participated in the present study, were employees of major IT market actors with a significant impact on the progress in the IT field. The Delphi method had two phases of interviews and questionnaires, whereas the first part of the interviews referred to the current software development models of the companies and the second part referred to differences in management and trends of software development models for the next five years. The specialists, who were interviewed had been employed in their company for a period of: less than a year $(5 \%)$, one to three years $(53 \%)$, more than three years up to four years $(16 \%)$, more than five years $(26 \%)$. They were employed in specialized IT departments, that were responsible with the development of software for more fields, respectively: software for browsers, software for databases, anti-spam software, software for automated buildings, software for video games, software for payment systems, analytics tools, software for CRM, software for networking devices, software for telecom testing. Thus, the software development models analysed in the practical part can apply to all these fields and other fields from the IT sector. Some of the experts referred to present workplaces, as well as the situation of former workplaces, all being employed between 2011-2018 in the IT field in the field of software development.

Respondents were employed in organisations located in Romania, America, Switzerland, Austria and England. The aspect of the companies' regions are relevant as the study intends to research whether the same characteristics of the Waterfall and Agile model or unspecific elements apply for several companies located in different regions. The 19 experts interviewed were employees of 16 companies, out of which only one was a local Romanian company large sized, though, with 700 employees, the rest being multinational companies with international branches.

The main participating companies were: Google, Oracle, Avira Soft S.R.L., Freescale, Gameloft, Ubisoft, Luxoft, Ixia, Cargo Partner. The rest of the companies names cannot be revealed due to confidentiality reasons of the employees. The companies were divided according to the size in terms of number of employees: three participating companies had between 73000-387000 employees, four companies had between 10000-17300 employees, three companies had between 2000-6000 employees, four companies had 500 to 1700 employees and only two employed less than thirty people.

The practical research was performed between the 10th November 2017 and the 10th February 2018.

The main questions of the interviews and questionnaires referred to software development models in their companies, management differences in project and team management and future trends regarding software development models for the next five years. 


\section{EMPIRICAL RESULTS AND DISCUSSION}

The first finding of the study was that the most implemented model was the Agile model with its three forms, respectively: $68 \%$ of the experts mentioned Agile as the model used within their department, while the rest mentioned the Waterfall model, as illustrated in Figure 3. Only one expert mentioned both Waterfall and Agile are used within their department at the same time depending on the project.

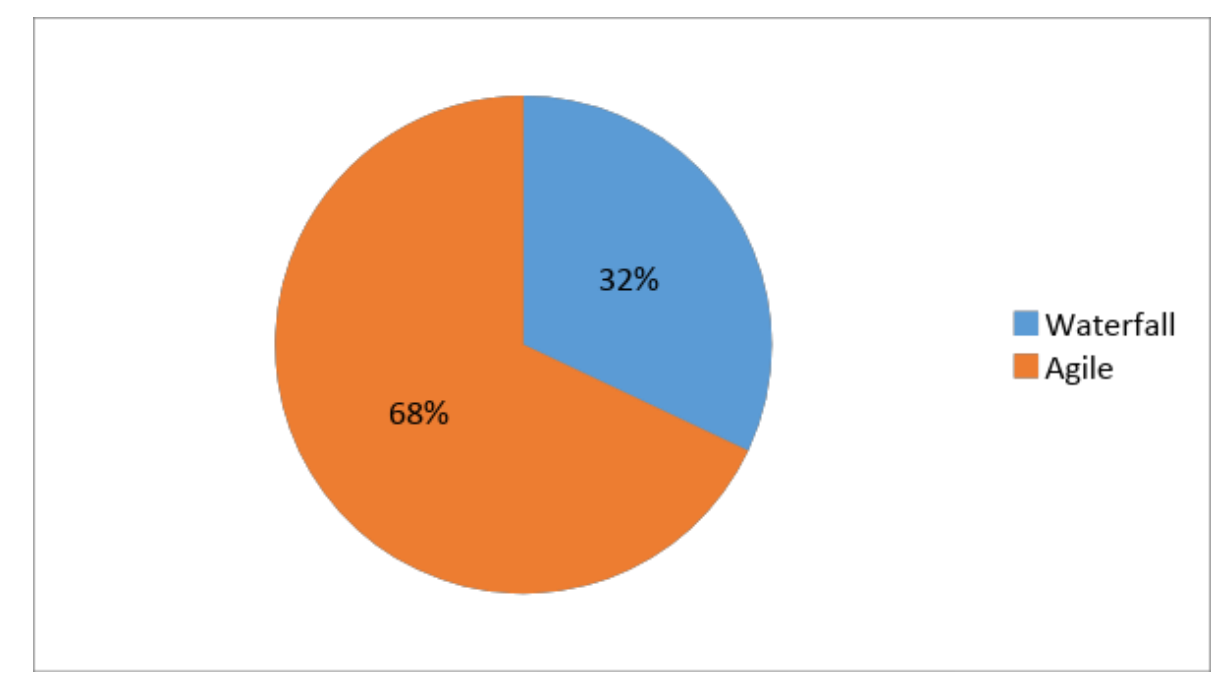

Figure 3. Waterfall vs. Agile software development models in the case of the selected experts

Source: Author's own research

From the ones that mentioned Agile 77\% mentioned the Agile Scrum was used in the case of their department, while 15\% mentioned Agile test driven development and the rest did not refer to a specific version of Agile, only mentioned Agile as the chosen model of their department. $50 \%$ of the persons that mentioned the Waterfall was used within their department were working between the years 2006-2012 at most, while half of these mentioned the Agile model was implemented after 2011 in their department. The trend of using the Agile model was mentioned as being an imperative from the perspective of their departments' and companies' management in order to adapt quickly to customer needs and the production of continuously improved products.

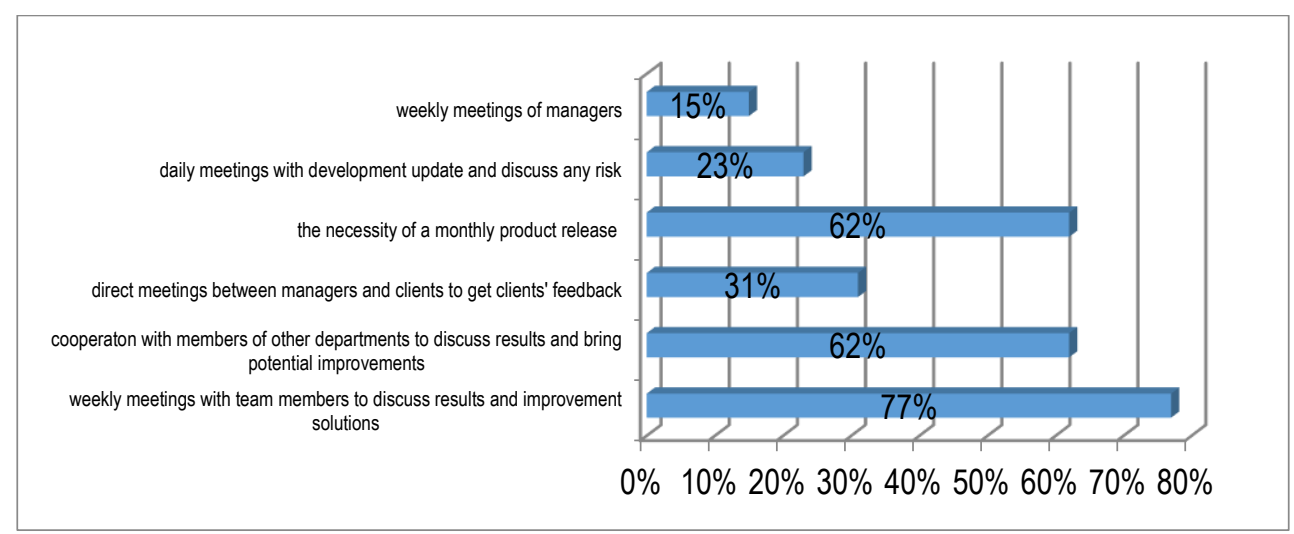

Figure 4. Specific management of product development in the participating IT companies of the study

Source: author's own research 
Specific characteristics of the implemented Agile models within the companies selected for the study, that were mentioned by the experts included specific general features of the Agile model theory, as well as specific elements depending on the firm such as: monthly analysis of requirements, monthly releases, daily stand-up meetings, sprints, deliverables every two weeks, feedback from the creative team, cooperation of the software developers with other departments, for example with employees, who write product features in order to get to an agreement, depending on the first features implementation, constant contact with the customers to evaluate progress and receive further improvement suggestions.

As one can observe in Figure 4, most companies (77\%) using Agile mentioned weekly meetings with team members to discuss results and possible further improvement solutions of the software products. This implied weekly meetings of the software development team members and the managers (usually local managers) in order to present the progress in the product development and priorities for the following improvements are discussed. The software developers can present their achievements in the software development progress, but also the obstacles in the process, in order to obtain or discuss possible solutions. The Agile model was considered through the descriptions as a dynamic model, that could add pressure on employees through the frequent evaluation of progress, but on the other side as motivating for selfimprovement and adapting to customer requirements. In the case of $63 \%$ the teams and their managers (using Agile) had to cooperate with members of other departments for further improvement of the software. The ones mentioned in the interviews were: the sales department, the customer communication department and the creative team. These departments in most cases provided the feedback of the customers to the IT team and/or communicated with customers to obtain insight into their requirements regarding future software products/and or releases. $15 \%$ of the specialists mentioned there was a weekly meeting of the managers with other managers (scrum of scrums) for discussions regarding future directions in software development.

$62 \%$ of the experts teams had to present a monthly product release, which implied every month an improved software release version had to be added. $23 \%$ of the participants did not mention any specific characteristics of the Agile models their companies used, just mentioned Agile and their characteristics, however, these were included in the features described in Figure 4.

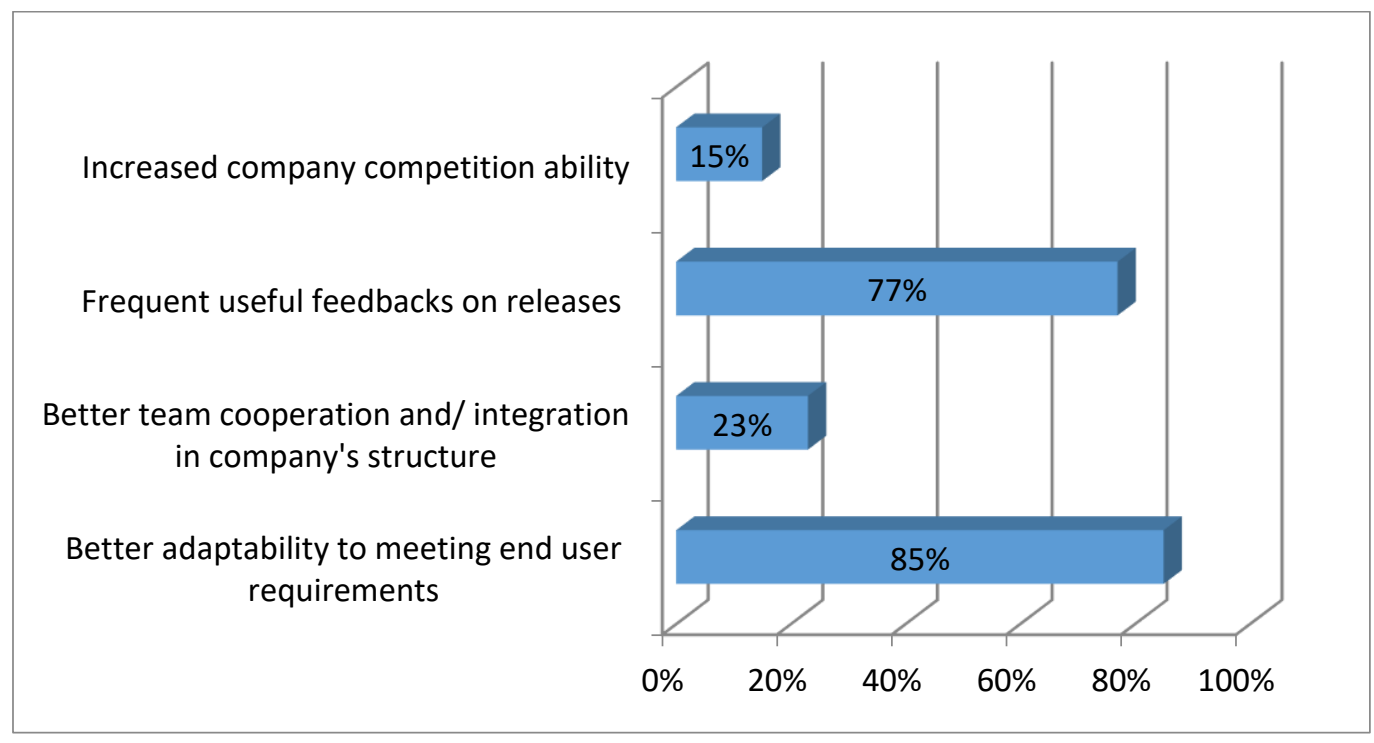

Figure 5. Advantages of the Agile model in the selected companies

Source: Authors' own research 
When asked about advantages of using the Agile model and/ or replacing the Waterfall model with Agile model as in the case of some participants, most participants using Agile (85\%) mentioned the better ability to adapt to meeting end user requirements through a dynamic feedback and product improvements as one of the main advantages. Most experts mentioned the customers were practically involved in the production process in terms of evaluating frequently (such as monthly) the new product features and providing valuable feedback on potential new improvements for a future version. The experts mentioned a closed cooperation between the company and the clients in order to get quickly improved products. $77 \%$ of the participants considered Agile brought frequent useful feedback on product releases, that could further contribute to improving products in the future.

$23 \%$ of the specialists mentioned the agile model contributed to better team cooperation and better team integration in the company's structure.

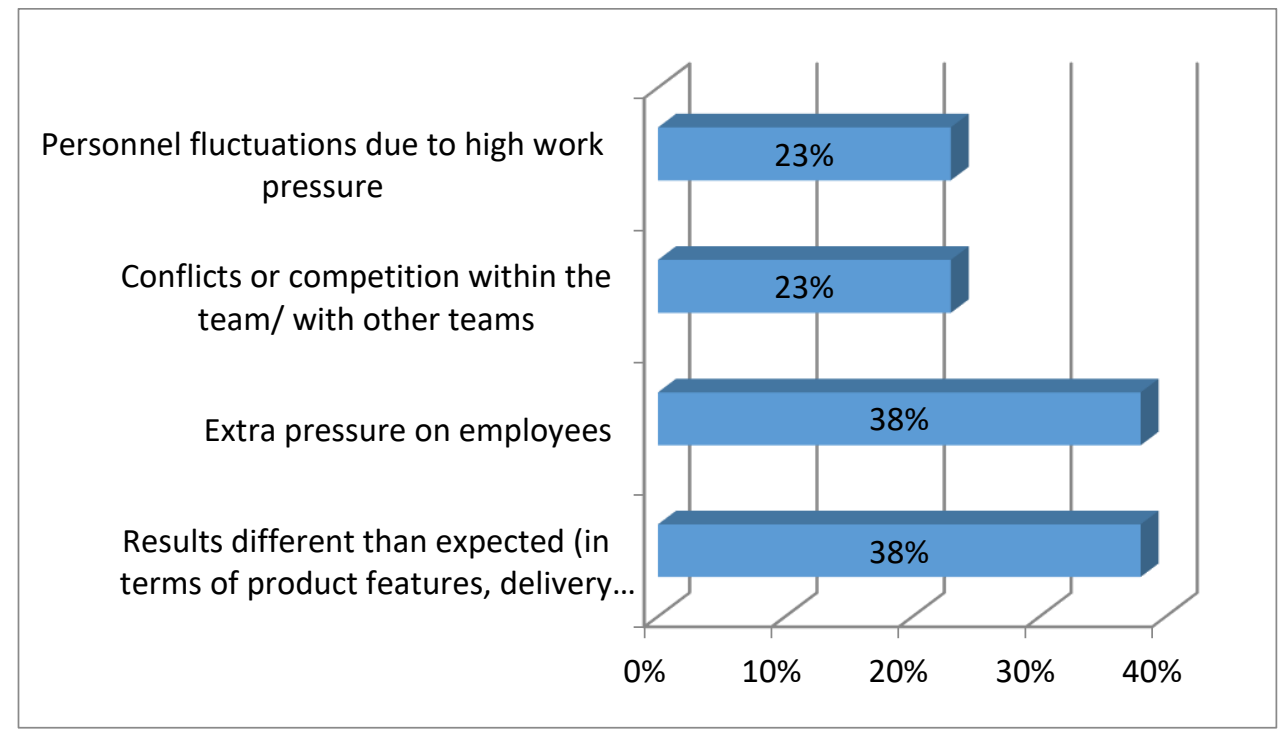

Figure 6. Disadvantages regarding the Agile model within the selected companies Source: Authors' own research

The participating experts using the Agile model in software development also referred to certain disadvantages using this model, the most important ones being extra pressure on employees (38\%) due to the necessity of frequent implementation of customer required improvement feature and the problem of results differing from certain expected terms, especially in the case of the delivery time, as one can notice in Figure 6. 23\% of the experts mentioned personnel fluctuations due to high work pressure as Agile was implemented and used in their company. Conflicts or competition within the team or between teams was also observed, the specialists mentioning communication problems or lacking share of knowledge or information in certain cases in the teams.

However these problems were not emphasized as being major obstacles for product development, more as a consequence of the necessity of a fast working pace.

The IT experts were further interviewed as an overall image of the Agile versus the Waterfall model implementation and have mentioned the differences illustrated in Table 1 as the most significant ones. First of all Agile was considered a more dynamic model comparing to the Waterfall model, where software developers usually receive requirements and go through all phases of the production before release and customer feedback. Agile requires a more dynamic work pace, where frequent customer improvement suggestions are implemented along the releases, that occured in most companies cases monthly. 
Furthermore, Agile models allow customer involvement in production through product evaluation and the chance to suggest further features, improvements, etc. This way the company product was considered to adapt better and continuously to customer requirements.

Table 1

Differences in project management in the Agile vs. The Waterfall Model as described by the interviewed experts

\begin{tabular}{|l|l|}
\hline \multicolumn{1}{|c|}{ Waterfall model } & \multicolumn{1}{c|}{ Agile model } \\
\hline $\begin{array}{l}\text {-formal, hierarchical organisation and transfer of } \\
\text { information (top- down) }\end{array}$ & $\begin{array}{l}\text { - informal organisational culture (frequent } \\
\text { communication managers, employees, departments) }\end{array}$ \\
\hline $\begin{array}{l}\text {-customer receives product at the end of the software } \\
\text { development process, then feedback }\end{array}$ & -customer involved in production \\
\hline $\begin{array}{l}\text {-customer feedback received after delivery of end } \\
\text { product }\end{array}$ & $\begin{array}{l}\text {-customer feedback on product releases and } \\
\text { improvement suggestions (usually monthly) required }\end{array}$ \\
\hline -product released at the end of all production phases & -frequent releases (usually monthly) \\
\hline -often no cooperation with other departments & $\begin{array}{l}\text {-often cooperation with other departments to achieve } \\
\text { customer insight and satisfaction }\end{array}$ \\
\hline -less frequent presentation of results & $\begin{array}{l}\text {-pressure on employees to present (weekly, every two } \\
\text { weeks, etc.) progress in project development }\end{array}$ \\
\hline
\end{tabular}

Source: Authors' own research.

$27 \%$ of the participating experts mentioned the possibility of creating new improved products as a main motivating factor in the case of the Agile model used in their company. 40\% mentioned the chance to express and implement a part of their ideas suggested to managers and/or clients, $6 \%$ mentioned financial motivation, such as bonuses. Others mentioned learning new things and cooperation with other departments, or mentioned no answer. Only one employee mentioned no motivating factor in working with Agile.

An unexpected finding was that most experts working with Waterfall in their departments $(67 \%)$ mentioned characteristics indicating an orientation towards the Agile model, such as receiving constantly customer feedback. The rest of the experts $(23 \%)$ using Waterfall mentioned the traditional form of this model where the top management transmits the product requirements and the developers work according to very well-defined criteria and rules and deliver products being followed by customer feedback. They mentioned they were not in close contact with customer feedbacks and received it after product delivery, usually from the management or sales department. An observation would be that these latter employees worked before 2013 with Waterfall, while the $67 \%$ of the employees mentioning Agile characteristics within the Waterfall model were working currently or after 2013.

Regarding trends in software development for the next five years $37 \%$ mentioned the agile model as a trend for the next five years, $15 \%$ mentioned new models emerging, $11 \%$ mentioned the companies will keep the models they started with as changes to a new model are difficult, while $37 \%$ did not answer or did not know.

\section{DISCUSSION}

The study focused on the usage of two of the main software development models in the IT field, respectively Agile and Waterfall. Some main points of the research were: the evolution of characteristics of these models within 2006-2018, perceived advantages of usage of the software development models by 
employees of the selected companies, unspecific characteristics of the development models, trends expected in the next five years.

As mentioned in the Findings the Agile model prevailed as the main model to be used in the interviewed companies. An interesting fact was that in the case of $67 \%$ of the experts, that used the Waterfall model, a specific characteristic of the Agile model was implemented, namely the frequent contact with the customers and/or stakeholders. The participating experts in these companies mentioned a tendency of adaptation of the Waterfall model towards Agile in the direction of more focus on environmental changes and customer or stakeholders' needs.

Although Agile is described in the scientific literature as most commonly having benefits for the companies and the customers or stakeholders, the present study revealed indeed the perceived advantage of more orientation and adapting towards customer or stakeholders needs, but also more pressure on employees, that can decrease motivation and eventually lead to personnel fluctuations.

Regarding trends although the Agile model was the main type expected to be dominating the management model of software development, $15 \%$ of the experts mentioned new models emerging from the existing ones. This evolution of the software development models is a main topic for future research and a subject worthy of debate as the IT market becomes more dynamic, as well as the digitalization process.

Although the Agile model has several benefits as mentioned also by the experts in the research, such as: frequent contact with the customer, cooperation between teams, more evaluations of the progress towards proposed objectives, a main issue represents the pressure of the employees, that have to overcome an increased pressure from the environment. Some of the main issues stated by the participating experts were: conflicts and demotivation of employees (15,7\%), time consuming and lacking planning (37\%), other or no answer the rest of the employees. A solution for the time consumption and poor planning of this model could be based on adjustable milestones (times and/or deliverables) for when the work volume has been wrongly estimated, overhead for planning meetings, overhead for preparing end of sprint releases. As in the case of motivation of employees financial motivation, such as bonuses and involvement of employees in end decisions could be a solution in order to decrease the Agile working dissatisfaction.

The study has its limitations based on the sample mentioned, however, as the participating companies represent some of the main players in the IT field, it offers an overview of the situation of the Waterfall and Agile models.

\section{CONCLUSION}

In this paper we aimed to research the software development models in companies from the IT sectors and their impacts on management between 2006-2018. As a conclusion the first hypothesis that after 2013 the agile model was the main software development model used was proven true in the case of the selected companies, that participated in the study. Furthermore, most participants that mentioned waterfall models after 2013 mentioned they implemented characteristics of the agile model, such as frequent customer feedback involvement, leading to a radical change in the direction of incremental changes according to customer requirements. The second hypothesis that in the future the Agile model, as well as other new, emerging software development models will define this field in the next five years was also confirmed as $52 \%$ of the participants mentioned one of the two alternatives.

The IT sector is facing new challenges in the next years as requirements from different stakeholders and fields are increasing and needs therefore, innovation not only in terms of product development, but also in terms of management models, that ensure a successful cooperation between teams and managers, the main objective being the customer satisfaction and not formal connections. This implies the need for frequent cooperation between managers, employees and other departments in several IT companies, in 
order to establish main customer requirements, orderly and innovative structures of organizing project development and adding customer feedback and involvement in the production process. Thus, the production process is no longer viewed in a static way from requirements analysis to design, implementation and only afterwards customer feedback, but allows and encourages customer involvement in the process.

A future research objective of the present study would be to observe the evolution of these IT software development models and their changes on companies' management for the next years and how they will evolve and lead to potential new models. This subject will be of interest as organizational cultures and management strategies could change thoroughly and affect employees behaviour and company perspective towards customers and other stakeholders.

\section{REFERENCES}

Ashishdeep, A., Bhatia, J., \& Varma, K. (2015). Software process models for mobile application development : A review, IJCSC, 7(1), 150-153, DOI: 10.090592/IJCSC.2016.020.

Canty, D. (2015). Agile for Project Managers. Florida, CRC Press.

Chandra, V. (2015). Comparison between Various Software Development Methodologies, International Journal of Computer Applications, 131(9), 7-10, Retrieved May 25th, 2018, from: https:/ / www.ijcaonline.org/research/volume131/ number9/chandra-2015-ijca-907294.pdf.

Chandrasekara, C. (2017). Beginning Build and Release Management with TFS 2017 and VSTS: Leveraging Continuous Delivery for Your Business. Sri Lanka, APRESS.

Cobb, C.G. (2015). The Project Manager's Guide to Mastering Agile: Principles and Practices for an adaptive approach, New Jersey, John Wiley \& Sons.

Comptia. (2018). IT industry outlook. https://www.comptia.org/resources/it-industry-trends-analysis.

Kaur, R., \& Sengupta, J. (2011). Software Process Models and Analysis on Failure of Software Development Projects. International Journal of Scientific \& Engineering Research, 2(2), 1-4.

Kihlström, G. (2016). The Agile Web: A Challenge to Re-Examine the Methods and Processes Used to Plan, Enhance and Optimize websites. Vancouver, Carousel30.

Krishna, S.T, Sreekanth, S., Perumal, K., \& Reddy, K.R.K (2012). Explore 10 different types of software development process model. International Journal of Computer Science and Information Technologies, 3(4), 4580-4584.

Linz, T. (2014). Testing in Scrum: A Guide for Software Quality Assurance in the Agile World. Rocky Nook, California.

McHugh, M., Cawley, O., McCaffery, F., Richardson, I., \& Wang, X. (2013). An Agile V-Model for Medical Device Software Development to Overcome the Challenges with Plan-Driven Software Development Lifecycles. IEEE, Retrieved 20 May $2018, \quad$ from: http:/ / users.jpu.fi/ mieijala / kandimateriaali/ An\%20 Agile \%20V\%20model\%20for\%20medical\%20soft.pdf

Othman, M. Ismail, M.H., \& Wahab, N.A. (2017). Computing Research \& Innovation (CRINN) Vol 2. Perlis Branch, University Teknologi Mara.

Paranj, B. (2017). Test Driven Development in Ruby: A Practical Introduction to TDD Using Problem and Solution Domain Analysis. Georgia, APRESS.

Puri, C.P. (2009). Agile Management: Feature Driven Development. New Delhi, Global India Publications Pvt Ltd.

Pycek, R. (2009). Suitability of Modern Software Development Methodologies for Model Driven Development. JIOS, 33, 285-295.

Stober, T., \& Hansmann, U. (2010). Agile Software Development: Best Practices for Large Software Development Projects. Berlin, Springer Verlag.

Vallabhaneni, R.S. (2018). Wiley CLAexcel Exam Review 2018, Part 3: Internal Audit Knowledge Elements. New Jersey, John Wiley \& Sons.

Westfall, L. (2010). The Certified Software Quality Engineer Handbook. Milwaukee, Quality Press. 